\title{
On the Approximation of Functions of Several Variables ${ }^{1}$
}

\author{
B. Mond ${ }^{2}$ and O. Shisha ${ }^{2}$ \\ Aerospace Research Laboratories, Wright-Patterson AFB, Ohio
}

(May 24, 1966)

\begin{abstract}
The purpose of this note is to point out how a certain type of approximation to functions of one real variable gives rise to similar approximations to functions of several variables. Information on the rapidity of convergence in the one dimensional case, yields at once corresponding information for the multidimensional case.
\end{abstract}

Key Word: Approximations, convergence, multidimensional, polynomials, functions, variables, Hermite-Fejér, Bernstein, Chebyshev.

1. The purpose of this note is to point out how a certain type of approximation to functions of one real variable, gives rise to similar approximations to functions of several variables. In fact, we show how information on the rapidity of convergence of the approximation in the one dimensional case, yields at once corresponding information for the multidimensional case.

2. Let $-\infty<a<b<\infty$, and for $n=1,2, \ldots$, let $c_{\alpha}^{(n)}, c_{1}^{(n)}, \ldots, c_{n}^{(n)}$ be points of $[a, b]$, and $K_{0}^{(n)}(x), K_{1}^{(n)}(x), \ldots, K_{n}^{(n)}(x)$ polynomials which are $\geqslant 0$ throughout $[a, b]$, and such that

$$
\sum_{j=0}^{n} K_{j}^{(n)}(x) \equiv 1
$$

We set, finally, for every real function $f$, continuous in $[a, b]$,

$$
P_{n}(f, x) \equiv \sum_{j=0}^{n} f\left(c_{j}^{(n)}\right) K_{j}^{(n)}(x) \quad(n=1,2, \ldots) .
$$

3. The purpose of constructing such polynomials $P_{n}(f, x)$ is to obtain polynomial approximations to $f$. Here are two examples.

I. Let $a=0, b=1$, and for $n=1,2, \ldots$, let $c_{j}^{(n)}=j / n, K_{j}^{(n)}(x) \equiv\left(\begin{array}{l}n \\ j\end{array}\right) x^{j}(1-x)^{n-j}(j=0,1, \ldots, n)$. Then $\sum_{j=0}^{n} K_{j}^{(n)}(x) \equiv 1(n=1,2, \ldots)$. If $f$ is any real function, continuous in $[0,1]$, then for $n=1.2, \ldots$.

$$
P_{n}(f, x) \equiv \sum_{j=0}^{n} f\left(c_{j}^{(n)}\right) K_{j}^{(n)}(x) \equiv \sum_{j=0}^{n} f(j / n)\left(\begin{array}{c}
n \\
j
\end{array}\right) x^{j}(1-x)^{n-j}
$$

is the Bernstein polynomial [1] of order $n$ of $f$. If, furthermore, $\omega(\delta)$ is the modulus of continuity of $f$ in $[0,1]$, then $([7,10])$ the polynomial $(2)$ satisfies

$$
\max _{0 \leq x \leq 1}\left|f(x)-P_{n}(f, x)\right| \leqslant(5 / 4) \omega\left(n^{-1 / 2}\right) \quad(\mathrm{n}=1,2, \ldots .) .
$$

\footnotetext{
${ }^{1}$ An invited paper.

${ }^{2}$ Aerospace Research Laboratories, Bldg. 450, Wright-Patterson AFB, Ohio 45433.
} 
II. Let $a=-1, b=1$, and for $n=1,2, \ldots$, let $c_{j}^{(n)}=\cos \left[\frac{2 j+1}{2(n+1)} \pi\right]$,

$$
K_{j}^{(n)}(x) \equiv\left(1-c_{j}^{(n)} x\right)\left[T_{n+1}(x) /\left\{(n+1)\left(x-c_{j}^{(n)}\right)\right\}\right]^{2} \quad(j=0,1, \ldots, n),
$$

where $T_{n+1}(x) \equiv 2^{n} \prod_{k=0}^{n}\left(x-c_{k}^{(n)}\right)$ is the $(n+1)$ th degree Chebyshev polynomial of the first kind satisfying $T_{n+1}(\cos \theta) \equiv \cos [(n+1) \theta]$. If $f$ is any real function continuous in $[-1,1]$, then

$$
P_{n}(f, x) \equiv \sum_{j=0}^{n} f\left(c_{j}^{(n)}\right) K_{j}^{(n)}(x) \equiv \sum_{j=0}^{n} f\left(c_{j}^{(n)}\right)\left(1-c_{j}^{(n)} x\right)\left[T_{n+1}(x) /\left\{(n+1)\left(x-c_{j}^{(n)}\right)\right\}\right]^{2}
$$

$(n=1,2, \ldots .$.$) are the well-known [3] Hermite-Fejér polynomials converging uniformly to f$ in $[-1,1]$. Again $\sum_{j j=0}^{n} K_{j}^{(n)}(x) \equiv 1(n=1,2, \ldots)$. If $f$ is a real function, satisfying throughout $[-1,1]$

$$
|f(v)-f(u)| \leqslant \lambda|v-u|
$$

where $\lambda$ is a positive constant, then [11] for $n=1,2, \ldots$

$$
\max _{-1 \leqslant x \leqslant 1}\left|f(x)-P_{n}(f, x)\right|<4 \lambda \pi(n+1)^{-1}[\alpha+\log (n+1)]
$$

where $\alpha=\frac{1}{2}+C-\log 2=0.384 \ldots, C$ being Euler's constant. Furthermore, if $f$ is a real function, continuous in $[-1,1]$, and if $\omega(\delta)$ is the modulus of continuity of $\bar{f}$ there, then for $n=1,2, \ldots$ we have [11]

$$
\max _{-1 \leqslant x \leqslant 1}\left|f(x)-P_{n}(f, x)\right| \leqslant\left[2+4 \pi+\eta_{n}\right] \omega\left(\frac{\log (n+1)}{n+1}\right)
$$

where $\eta_{n}$ depends on $n$ only and $\eta_{n} \rightarrow 0$ as $n \rightarrow \infty$.

4. TheOREM 1. Assume the hypotheses and notation of section 2. Assume also that if $\mathrm{f}$ is a real function satisfying for some positive constant $\lambda$, throughout $[\mathrm{a}, \mathrm{b}],|\mathrm{f}(\mathrm{v})-\mathrm{f}(\mathrm{u})| \leq \lambda|\mathrm{v}-\mathrm{u}|$, then for $\mathrm{n}=1,2, \ldots$

$$
\max _{a \leqslant x \leqslant b}\left|f(x)-P_{n}(f, x)\right|<a_{\lambda, n}
$$

where $\mathrm{a}_{\lambda, \mathrm{n}}$ depends on $\lambda$ and $\mathrm{n}$ only. Let $\mathrm{f}\left(\mathrm{x}_{1}, \mathrm{x}_{2} \ldots, \mathrm{x}_{\mathrm{p}}\right)(\mathrm{p} \geqslant 2)$ be a real function, defined on the cube C: $\mathrm{a} \leqslant \mathrm{x}_{\mathrm{k}} \leqslant \mathrm{b}, \mathrm{k}=1,2$, . ., p. Suppose that for $\mathrm{r}=1,2, \ldots, \mathrm{p}, \lambda_{\mathrm{r}}$ is a positive number such that throughout $C$

$\left|f\left(x_{1}, x_{2}, \ldots, x_{r-1}, v, x_{r+1}, \ldots, x_{p}\right)-f\left(x_{1}, x_{2}, \ldots, x_{r-1}, u, x_{r+1}, \ldots, x_{p}\right)\right| \leqslant \lambda_{r}|v-u|$

Let $\mathrm{n}_{1}, \mathrm{n}_{2}, \ldots, \mathrm{n}_{\mathrm{p}}$ be arbitrary positive integers, and set

$\mathrm{P}_{\mathrm{n}_{1}, \mathrm{n}_{2}, \ldots, \mathrm{n}_{\mathrm{p}}}\left(\mathrm{f}, \mathrm{x}_{1}, \mathrm{x}_{2}, \ldots, \mathrm{x}_{\mathrm{p}}\right) \equiv \sum_{\mathrm{h}_{1}=0}^{\mathrm{n}_{1}} \ldots \sum_{\mathrm{h}_{\mathrm{p}}=0}^{\mathrm{n}_{\mathrm{p}}} \mathrm{f}\left(\mathrm{c}_{\mathrm{h}_{1}}^{\left(\mathrm{n}_{1}\right)}, \ldots, \mathrm{c}_{\mathrm{h}_{\mathrm{p}}}^{\left(\mathrm{n}_{\mathrm{p}}\right)}\right) \mathrm{K}_{\mathrm{h}_{1}}^{\left(\mathrm{n}_{1}\right)}\left(\mathrm{x}_{1}\right) \ldots \mathrm{K}_{\mathrm{h}_{\mathrm{p}}}^{\left(\mathrm{n}_{\mathrm{p}}\right)}\left(\mathrm{x}_{\mathrm{p}}\right)$

Then throughout $C$ :

$$
\left|f\left(x_{1}, x_{2}, \ldots x_{p}\right)-P_{n_{1}, n_{2}, \ldots, n_{p}}\left(f, x_{1}, x_{2}, \ldots, x_{p}\right)\right|<\sum_{r=1}^{p} a_{\lambda_{r}}, n_{r} .
$$


Proof. Observe that $\sum_{h_{1}=0}^{n_{1}} \ldots \sum_{h_{p}=0}^{n_{p}} K_{h_{1}}^{\left(n_{1}\right)}\left(x_{1}\right) \ldots K_{h_{p}}^{\left(n_{p}\right)}\left(x_{p}\right) \equiv 1$.

Hence, throughout $C$,

$$
\begin{aligned}
& f\left(x_{1}, \ldots ., x_{p}\right)-P_{n_{1}, n_{2}}, \ldots, n_{p}\left(f, x_{1}, x_{2}, \ldots, x_{p}\right) \\
& =\sum_{h_{1}=0}^{n_{1}} \ldots \sum_{h_{p}=0}^{n_{p}}\left[f\left(x_{1}, \ldots ., x_{p}\right)-f\left(c_{h_{1}}^{\left(n_{1}\right)}, \ldots, c_{h_{p}}^{\left(n_{p}\right)}\right)\right] K_{h_{1}}^{\left(n_{1}\right)}\left(x_{1}\right) \ldots K_{h_{p}}^{\left(n_{p}\right)}\left(x_{p}\right) \\
& =\sum_{h_{1}=0}^{n_{1}} \ldots \sum_{n_{p}=0 \mid}^{n_{p}}\left\{\sum_{r=1}^{p}\left[f\left(c_{h_{1}}^{\left(n_{1}\right)}, \ldots, c_{h_{r-1}}^{\left(n_{r-1}\right)}, x_{r}, \ldots, x_{p}\right)-f\left(c_{h_{1}}^{\left(n_{1}\right)}, \ldots, c_{h_{r}}^{\left(n_{r}\right)}, x_{r+1}, \ldots, x_{p}\right)\right]\right\} \\
& \cdot \prod_{s=1}^{p} K_{h_{s}}^{\left.n_{s}\right)}\left(x_{s}\right) \\
& =\sum_{r=1}^{p} \sum_{\substack{h_{q}=0,1, \ldots, n_{q} \\
q=1,2, \ldots, p, q \neq r}}\left\{\sum_{h_{r}=0}^{n_{r}}\left[f\left(c_{h_{1}}^{\left(n_{1}\right)}, \ldots, c_{h_{r-1}}^{\left(n_{r-1}\right)}, x_{r}, \ldots, x_{p}\right)-f\left(c_{h_{1}}^{\left(n_{1}\right)}, \ldots, c_{h_{r}}^{\left(n_{r}\right)}, x_{r+1}, \ldots ., x_{p}\right)\right]\right. \\
& \left.\cdot K_{h_{r}}^{\left(n_{r}\right)}\left(x_{r}\right)\right\} \prod_{\substack{s=1 \\
s \neq r}}^{p} K_{h_{s}}^{\left(n_{s}\right)}\left(x_{s}\right)
\end{aligned}
$$

$\left(f\left(c_{h_{1}}^{\left.n_{1}\right\}}, \ldots, c_{h_{r-1}}^{\left(n_{r-1}\right)}, x_{r}, \ldots, x_{p}\right)\right.$ means $f\left(x_{1}, \ldots, x_{p}\right)$ if $r=1$, and

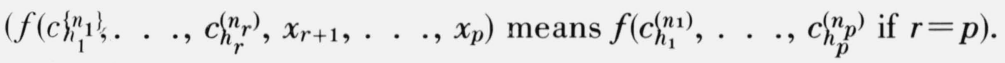

Thus, throughout $C$,

$$
\begin{aligned}
& \left|f\left(x_{1}, \ldots ., x_{p}\right)-P_{n_{1}, n_{2}, \ldots, n_{p}}\left(f, x_{1}, \ldots, x_{p}\right)\right| \\
& \leqslant \sum_{r=1}^{p} \sum_{\substack{h_{q}=0,1, \ldots, n_{q} \\
q=1,2, \ldots, p, q \neq r}} \mid f\left(c_{h_{1}}^{\left(n_{1}\right)}, \ldots, c_{h_{r-1}}^{\left(n_{r-1}\right)}, x_{r}, \ldots, x_{p}\right)-\sum_{h_{r}=0}^{n_{r}} f\left(c_{h_{1}}^{\left(n_{1}\right)}, \ldots, c_{h_{r}}^{(n)}, x_{r+1}, \ldots, x_{p}\right) \\
& \cdot K_{h_{r}}^{\left(n_{r}\right)}\left(x_{r}\right) \mid \prod_{\substack{s=1 \\
s \neq r}}^{p} K_{h_{s}}^{\left(n_{s}\right)}\left(x_{s}\right) \\
& <\sum_{r=1}^{p} \sum_{\substack{h_{q}=0,1, \ldots, n_{q} \\
q=1,2, \ldots, p, q \neq r}} a_{\lambda_{r}, n_{r}} \prod_{\substack{s=1 \\
s \neq r}}^{p} K_{h_{s}}^{\left(n_{s}\right)}\left(x_{s}\right)=\sum_{r=1}^{p} a_{\lambda_{r}, n_{r}} .
\end{aligned}
$$

5. Example [11]. Let $f\left(x_{1}, x_{2}, \ldots, x_{p}\right)(p \geqslant 2)$ be a real function defined on the cube $C$ : $-1 \leqslant x_{k} \leqslant 1, k=1,2, \ldots, p$. Suppose that for $r=1,2, \ldots, p$ we have, for some positive constant $\lambda_{r}$ and throughout $C$, the inequality (3). For $j=0,1, \ldots, n ; n=1,2, \ldots$., let $c_{j}^{(n)}$ and $K_{j}^{(n)}(x)$ be as in II, section 3. If $n_{1}, n_{2}, \ldots, n_{p}$ are positive integers and $\boldsymbol{P}_{n_{1}, n_{2}}, \ldots, n_{p}\left(f, x_{1}, \ldots, x_{p}\right)$ is defined by (4), then by Theorem 1 we have, throughout $C$,

$$
\left|f\left(\mathbf{x}_{1}, \ldots, x_{p}\right)-P_{n_{1}}, \ldots, n_{p}\left(f, x_{1}, \ldots, x_{p}\right)\right|<\sum_{r=1}^{p} 4 \lambda_{r} \pi\left(n_{r}+1\right)^{-1}\left[\alpha+\log \left(n_{r}+1\right)\right] .
$$


6. Similarly to Theorem 1, one can prove the following

Theorem 2. Assume the hypotheses and notation of Section 2. Assume also that for $\mathrm{n}=1,2$, . . , $\alpha_{\mathrm{n}}, \beta_{\mathrm{n}}\left(\beta_{\mathrm{n}} \leqslant \mathrm{b}-\mathrm{a}\right)$ are numbers such that if $\mathrm{f}$ is a real function, continuous in [a, b], with modulus of continuity $\omega(\delta)$ there, then

$$
\max _{\mathrm{a} \leqslant \mathrm{x} \leqslant \mathrm{b}}\left|\mathbf{f}(\mathbf{x})-\mathrm{P}_{\mathrm{n}}(\mathrm{f}, \mathbf{x})\right| \leqslant \alpha_{\mathrm{n}} \omega\left(\beta_{\mathrm{n}}\right)
$$

Let $\mathrm{f}\left(\mathrm{x}_{1}, \mathrm{x}_{2}, \ldots, \mathrm{x}_{\mathrm{p}}\right)(\mathrm{p} \geqslant 2)$ be a real function, continuous in the cube $\mathrm{C}: \mathrm{a} \leqslant \mathrm{x}_{\mathrm{k}} \leqslant \mathrm{b}, \mathrm{k}=1,2, \ldots, \mathrm{p}$. For every $\delta \epsilon[0, \mathrm{~b}-\mathrm{a}]$ and every $\mathrm{r}(=1,2, \ldots, \mathrm{p})$, let

$$
\omega_{r}(\delta)=\max \left|f\left(x_{1}, \ldots, x_{r-1}, v, x_{r+1}, \ldots, x_{p}\right)-f\left(x_{1}, \ldots, x_{r-1}, u, x_{r+1}, \ldots, x_{p}\right)\right|
$$

where the $\mathrm{x}_{\mathrm{j}}, \mathrm{u}$, and $\mathrm{v}$ vary in $[\mathrm{a}, \mathrm{b}]$ with $0 \leqslant \mathrm{v}-\mathrm{u} \leqslant \delta$. Let $\mathrm{n}_{1}, \mathrm{n}_{2}, \ldots, \mathrm{n}_{\mathrm{p}}$ be arbitrary positive integers. Then with the notation (4), we have throughout $\mathrm{C}$,

$$
\left|\mathrm{f}\left(\mathrm{x}_{1}, \ldots ., \mathrm{x}_{\mathrm{p}}\right)-\mathrm{P}_{n_{1}, n_{2}}, \ldots, \mathrm{n}_{\mathrm{p}}\left(\mathrm{f}, \mathrm{x}_{1}, \ldots, \mathrm{x}_{\mathrm{p}}\right)\right| \leqslant \sum_{\mathrm{r}=1}^{\mathrm{p}} \alpha_{\mathrm{n}_{\mathrm{r}}} \omega_{\mathrm{r}}\left(\beta_{\mathrm{n}_{\mathrm{r}}}\right) .
$$

7. EXAmPle. Let $f\left(x_{1}, \ldots, x_{p}\right)(p \geqslant 2)$ be a real function, continuous in the cube $C: 0 \leqslant x_{k} \leqslant 1$, $k=1,2, \ldots, p$. For every $\delta \epsilon[0,1]$ and every $r(=1,2, \ldots, p)$ let $\omega_{r}(\delta)$ be as in Theorem 2 (with $a=0, b=1$ ). Let $n_{1}, \ldots, n_{p}$ be arbitrary positive integers. Then by Theorem 2, and by I, section 3 , we have throughout $C$ :

$$
\begin{array}{r}
\mid f\left(x_{1}, \ldots, x_{p}\right)-\sum_{h_{1}=0}^{n_{1}} \ldots \sum_{h_{p}=0}^{n_{p}} f\left(\frac{h_{1}}{n_{1}}, \ldots, \frac{h_{p}}{n_{p}}\right)\left(\begin{array}{l}
n_{1} \\
h_{1}
\end{array}\right) \ldots\left(\begin{array}{l}
n_{p} \\
h_{p}
\end{array}\right) x_{1}^{h_{1}} \ldots x_{p}^{h} p\left(1-x_{1}\right)^{n_{1}-h_{1}} \\
\cdots\left(1-x_{p}\right)^{n_{p}-h_{p}} \mid \leqslant \sum_{r=1}^{p}(5 / 4) \omega_{r}\left(n_{r}^{-1 / 2}\right) .
\end{array}
$$

8. We consider now an analog of the situation considered in Theorems 1 and 2 , sums being replaced by integrals.

9. Let $-\infty<a<b<\infty$, and for $n=1,2, \ldots$. let $K_{n}(x, t)$ be a real function which is $\geqslant 0$ and continuous in the square $a \leqslant x \leqslant b, a \leqslant t \leqslant b$, and which satisfies for every $x \in[a, b]$,

$$
\int_{a}^{b} K_{n}(x, t) d t=1
$$

For every real function $f$, continuous in $[a, b]$, set

$$
P_{n}(f, x) \equiv \int_{a}^{b} f(t) K_{n}(x, t) d t \quad(n=1,2, \ldots) .
$$

10. Such $P_{n}(f, x)$ are constructed again, like their counterparts (1), in order to obtain approximations to $f$. Here are a few examples of such $P_{n}(f, x)$ prominent in Analysis.

I. Let $a=-\pi, b=\pi$ and for every real $x, t$, let

$$
K_{n}(x, t)=\frac{1}{\pi}\left[-\frac{1}{2}+\sum_{j=0}^{n-1} \frac{n-j}{n} \cos \{j(t-x)\}\right] \quad(n=1,2, \ldots .)
$$

If $t-x$ is not an integral multiple of $2 \pi$, then

$$
K_{n}(x, t)=\sin ^{2}\left\{\frac{n}{2}(t-x)\right\} /\left[2 n \pi \sin ^{2}\left\{\frac{1}{2}(t-x)\right\}\right] \quad(n=1,2, \ldots .)
$$


Also the properties in the first sentence of section 9 hold. For every real function $f$ continuous in $(-\infty, \infty)$ and of period $2 \pi$, and for $n=1,2, \ldots, P_{n}(f, x)$ of $(7)$ is in the present case the arithmetic mean

$$
\sigma_{n}(f, x) \equiv n^{-1} \sum_{j=0}^{n-1} S_{j}(x)
$$

where

$$
\begin{gathered}
S_{0}(x) \equiv a_{0} / 2, \quad S_{j}(x) \equiv\left(a_{0} / 2\right)+\sum_{k=0}^{j}\left[a_{k} \cos (k x)+b_{k} \sin (k x)\right] \quad(j=1,2, \ldots), \\
\left(a_{0} / 2\right)+\sum_{k=0}^{\infty}\left[a_{k} \cos (k x)+b_{k} \sin (k x)\right]
\end{gathered}
$$

being the Fourier series of $f$, and by a classical theorem of Fejér [2] $\sigma_{n}(f, x)$ converges uniformly to $f(x)$ in $(-\infty, \infty)$. Furthermore, suppose that a real function $f$ (of period $2 \pi$ ) satisfies throughout the real line, for some constant $\lambda$,

$$
|f(v)-f(u)| \leqslant \lambda|v-u|
$$

Then by a theorem of S. N. Bernstein ([6], p. 61; [9], p. 162) for every $n>1, P_{n}(f, x) \equiv \sigma_{n}(f, x)$ satisfies

$$
\max _{-\infty<x<\infty}\left|f(x)-P_{n}(f, x)\right| \leqslant C_{0} \lambda \log n / n
$$

$C_{0}$ being an absolute constant.

II. Let $a=-\pi, b=\pi$, and for every real $x, t$, let

$$
K_{n}(x, t)=\frac{3}{2 \pi n\left(2 n^{2}+1\right)}\left[-n+2 \sum_{j=0}^{n-1}(n-j) \cos \{j(t-x)\}\right]^{2} \quad(n=1,2, \ldots .) .
$$

If $t-x$ is not an integral multiple of $2 \pi$, then

$$
K_{n}(x, t)=\frac{3}{2 \pi n\left(2 n^{2}+1\right)}\left[\frac{\sin \left\{\frac{n}{2}(t-x)\right\}}{\sin \left(\frac{t-x}{2}\right)}\right]^{4} \quad(n=1,2, \ldots .) .
$$

The properties in the first sentence of section 9 hold. For every real function $f$, continuous in $(-\infty, \infty)$ and of period $2 \pi$, and for $n=1,2, \ldots, P_{n}(f, x)$ of $(7)$ is now a trigonometric polynomial introduced by Jackson ([4,5,6]). If $f$ is a real function of period $2 \pi$, satisfying for every real $u, v$

$$
|f(v)-f(u)| \leqslant \lambda|v-u|
$$

$\lambda$ being a constant, then by a classical theorem of Jackson $([4,5,6])$ this particular $P_{n}(f, x)$ satisfies .

$$
\max _{-\infty<x<\infty}\left|f(x)-P_{n}(f, x)\right| \leqslant(c \lambda / n) \quad(n=1,2, \ldots),
$$

$c$ being an absolute constant. 
III. Let $a=-\pi, b=\pi$, and for every real $x, t$, let

$$
K_{n}(x, t)=\frac{(2 n) ! !}{2 \pi(2 n-1) ! !} \cos ^{2 n}\left(\frac{t-x}{2}\right) \quad(n=1,2, \ldots) .
$$

Here, $m$ !! denotes $2 \cdot 4 \cdot 6 \cdot \ldots m$ for every positive even $m$, and $1 \cdot 3 \cdot 5 . \ldots m$ for every positive odd $m$. Again the properties in the first sentence of section 9 hold. For every real function $f$, continuous and of period $2 \pi$ in $(-\infty, \infty)$ and for $n=1,2, \ldots, P_{n}(f, x)$ of $(7)$ is in the present case a trigonometric polynomial introduced by de la Valée-Poussin [12]. If $\omega(\delta)(0 \leqslant \delta<\infty)$ is the modulus of continuity of such an $f$, then ([8], [9]) for $n=1,2, \ldots$

$$
\max _{-\infty<x<\infty}\left|f(x)-P_{n}(f, x)\right| \leqslant 3 \omega\left(n^{-1 / 2}\right) .
$$

11. An analog of Theorem 1 is

THeOREM 3. Assume the hypotheses and notation of section 9. Assume also that if $\mathrm{f}$ is a real function satisfying for some positive constant $\lambda$, throughout $[\mathrm{a}, \mathrm{b}]$,

$$
|f(v)-f(u)| \leqslant \lambda|v-u|
$$

then for $\quad \mathrm{n}=1,2, \ldots \quad \max _{\mathrm{a} \leqslant \mathrm{x} \leqslant \mathrm{b}}\left|\mathrm{f}(\mathrm{x})-\mathrm{P}_{\mathrm{n}}(\mathrm{f}, \mathrm{x})\right|<\mathrm{a}_{\lambda, \mathrm{n}}$

where $\mathrm{a}_{\lambda, \mathrm{n}}$ depends on $\lambda$ and $\mathrm{n}$ only. Let $\mathrm{f}\left(\mathrm{x}_{1}, \mathrm{x}_{2}, \ldots, \mathrm{x}_{\mathrm{p}}\right)(\mathrm{p} \geqslant 2)$ be a real function defined in the cube C: $\mathrm{a} \leqslant \mathrm{x}_{\mathrm{k}} \leqslant \mathrm{b}, \mathrm{k}=1,2, \ldots, \mathrm{p}$. Suppose that for $\mathrm{r}=1,2, \ldots, \mathrm{p}, \lambda_{\mathrm{r}}$ is a positive number such that throughout $\mathrm{C}$

$$
\left|f\left(x_{1}, x_{2}, \ldots, x_{r-1}, v, x_{r+1}, \ldots, x_{p}\right)-f\left(x_{1}, x_{2}, \ldots, x_{r-1}, u, x_{r+1}, \ldots, x_{p}\right)\right| \leqslant \lambda_{r}|v-u| .
$$

Let $\mathrm{n}_{1}, \mathrm{n}_{2}, \ldots, \mathrm{n}_{\mathrm{p}}$ be arbitrary positive integers, and set

$$
\mathrm{P}_{n_{1}, n_{2}}, \ldots, \mathrm{n}_{\mathrm{p}}\left(\mathrm{f}, \mathrm{x}_{1}, \ldots, \mathrm{x}_{\mathrm{p}}\right) \equiv \int_{\mathrm{a}}^{\mathrm{b}} \ldots \int_{\mathrm{a}}^{\mathrm{b}} \mathrm{f}\left(\mathrm{t}_{1}, \ldots, \mathrm{t}_{\mathrm{p}}\right) \mathrm{K}_{\mathrm{n}_{1}}\left(\mathrm{x}_{1}, \mathrm{t}_{1}\right) \ldots \mathrm{K}_{\mathrm{n}_{\mathrm{p}}}\left(\mathrm{x}_{\mathrm{p}}, \mathrm{t}_{\mathrm{p}}\right) \mathrm{dt}_{1} \ldots \mathrm{dt}_{\mathrm{p}} .
$$

Then throughout $\mathrm{C}$ :

$$
\left|f\left(x_{1}, \ldots, x_{p}\right)-P_{n_{1}, n_{2}}, \ldots, n_{p}\left(f, x_{1}, \ldots, x_{p}\right)\right|<\sum_{r=1}^{p} a_{\lambda_{r}, n_{r}} .
$$

Proof. Observe that throughout C,

$$
\int_{a}^{b} \ldots \int_{a}^{b} K_{n_{1}}\left(x_{1}, t_{1}\right) \ldots K_{n_{p}}\left(x_{p}, t_{p}\right) d t_{1} \ldots d t_{p}=1
$$

Hence, throughout $C$,

$$
\begin{aligned}
& f\left(x_{1}, \ldots . x_{p}\right)-P_{n_{1}, n_{2}}, \ldots, n_{p}\left(f, x_{1}, \ldots, x_{p}\right) \\
& =\int_{a}^{b} \ldots \int_{a}^{b}\left[f\left(x_{1}, \ldots x_{p}\right)-f\left(t_{1}, \ldots ., t_{p}\right)\right] K_{n_{1}}\left(x_{1}, t_{1}\right) \ldots K_{n_{p}}\left(x_{p}, t_{p}\right) d t_{1} \ldots d t_{p} \\
& =\int_{a}^{b} \ldots \int_{a}^{b}\left[\sum_{r=1}^{p} f\left(t_{1}, \ldots ., t_{r-1}, x_{r}, \ldots ., x_{p}\right)-f\left(t_{1}, \ldots ., \dot{t_{r}}, x_{r+1}, \ldots, x_{p}\right)\right] K_{n_{1}}\left(x_{1}, t_{1}\right) \\
& \ldots K_{n_{p}}\left(x_{p}, t_{p}\right) d t_{1} \ldots d t_{p}
\end{aligned}
$$




$$
\begin{aligned}
=\sum_{r=1}^{p} \int_{a}^{b} \ldots & \int_{a}^{b}\left\{\int _ { a } ^ { b } \left[f\left(t_{1}, \ldots, t_{r-1}, x_{r}, \ldots, x_{p}\right)\right.\right. \\
& \left.\left.-f\left(t_{1}, \ldots ., t_{r}, x_{r+1}, \ldots, x_{p}\right)\right] K_{n_{r}}\left(x_{r}, t_{r}\right) d t_{r}\right\} \prod_{\substack{s=1 \\
s \neq r}}^{p} K_{n_{s}}\left(x_{s}, t_{s}\right) d t_{1} \ldots . d t_{r-1} d t_{r+1} \ldots . d t_{p} .
\end{aligned}
$$

$\left(f\left(t_{1}, \ldots, t_{r-1}, x_{r}, \ldots, x_{p}\right)\right.$ means $f\left(x_{1}, \ldots, x_{p}\right)$ if $r=1$, and $f\left(t_{1}, \ldots, t_{r}, x_{r+1}, \ldots, x_{p}\right)$ means $f\left(t_{1}, \ldots, t_{p}\right)$ if $\left.r=p\right)$. Thus, throughout $\mathrm{C}$,

$$
\begin{gathered}
\left|f\left(x_{1}, \ldots, x_{p}\right)-P_{n_{1}, n_{2}}, \ldots, n_{p}\left(f, x_{1}, \ldots, x_{p}\right)\right| \leqslant \sum_{r=1}^{p} \int_{a}^{b} \ldots \int_{a}^{b} \mid f\left(t_{1}, \ldots ., t_{r-1}, x_{r}, \ldots, x_{p}\right) \\
-\int_{a}^{b} f\left(t_{1}, \ldots, t_{r}, x_{r+1}, \ldots, x_{p}\right) K_{n_{r}}\left(x_{r}, t_{r}\right) d t_{r} \mid \prod_{\substack{s=1 \\
s \neq r}}^{p} K_{n_{s}}\left(x_{s}, t_{s}\right) d t_{1} \ldots . d t_{r-1} d t_{r+1} \ldots . d t_{p} \\
<\sum_{r=1}^{p} \int_{a}^{b} \ldots \int_{a}^{b} a_{\lambda_{r}, n_{r}} \prod_{\substack{s=1 \\
s \neq r}}^{p} K_{n_{s}}\left(x_{s}, t_{s}\right) d t_{1} \ldots d t_{r-1} d t_{r+1} \ldots . d t_{p}=\sum_{r=1}^{p} a_{\lambda_{r}, n_{r}} .
\end{gathered}
$$

Similarly, one can prove the following analog of Theorem 2:

Theorem 4. Assume the hypotheses and notation of section 9. Assume also that for $\mathrm{n}=1,2, \ldots$, $\alpha_{\mathrm{n}}, \beta_{\mathrm{n}}\left(\beta_{\mathrm{n}} \leqslant \mathrm{b}-\mathrm{a}\right)$ are numbers such that if $\mathrm{f}$ is a real function, continuous in $[\mathrm{a}, \mathrm{b}]$, with modulus of continuity $\omega(\delta)$ there, then

$$
\max _{a \leqslant x \leqslant b}\left|f(x)-P_{n}(f, x)\right| \leqslant \alpha_{n} \omega\left(\beta_{n}\right) .
$$

Let $\mathrm{f}\left(\mathrm{x}_{1}, \ldots, \mathrm{x}_{\mathrm{p}}\right)(\mathrm{p} \geqslant 2)$ be a real function, continuous in the cube $\mathrm{C}: \mathrm{a} \leqslant \mathrm{x}_{\mathrm{k}} \leqslant \mathrm{b}, \mathrm{k}=1,2, \ldots, \mathrm{p}$. For every $\delta \epsilon[0, \mathrm{~b}-\mathrm{a}]$ and every $\mathrm{r}(=1,2, \ldots, \mathrm{p})$ let $\omega_{\mathrm{r}}(\delta)$ be as in Theorem 2 . Let $\mathrm{n}_{1}, \ldots, \mathrm{n}_{\mathrm{p}}$ be arbitrary positive integers. Then with the notation (9), we have (6) throughout $\mathrm{C}$.

12. The last two theorems can obviously be modified in the following way. For $n=1,2, \ldots$. let $K_{n}(x, t)$ be a real function which throughout the plane $-\infty<x<\infty,-\infty<t<\infty$ is $\geqslant 0$, continuous, and of period $2 \pi$ with respect to $x$ and to $t$, and such that for every real $x$,

$$
\int_{-\pi}^{\pi} K_{n}(x, t) d t=1
$$

For every real function $f$, continuous and of period $2 \pi$ in $(-\infty, \infty)$, set

$$
P_{n}(f, x) \equiv \int_{-\pi}^{\pi} f(t) K_{n}(x, t) d t \quad(n=1,2, \ldots) .
$$

Let $f\left(x_{1}, \ldots, x_{p}\right)(p \geqslant 2)$ be a real function, continuous and of period $2 \pi$ with respect to each $x_{j}$ in the (real) Euclidean $p$-space $E_{p}$ : Let $n_{1}, n_{2}, \ldots, n_{p}$ be positive integers, and set

$$
P_{n_{1}}, \ldots, n_{p}\left(f, x_{1}, \ldots ., x_{p}\right) \equiv \int_{-\pi}^{\pi} \ldots \int_{-\pi}^{\pi} f\left(t_{1}, \ldots ., t_{p}\right) K_{n_{1}}\left(x_{1}, t_{1}\right) \ldots K_{n_{p}}\left(x_{p}, t_{p}\right) d t_{1} \ldots . d t_{p} .
$$


A. Suppose that if $f$ is a real function of period $2 \pi$, satisfying for some constant $\lambda$, throughout $(-\infty, \infty),|f(v)-f(u)| \leqslant \lambda|v-u|$, then for $n=1,2, \ldots$

$$
\max _{-\infty<x<\infty}\left|f(x)-P_{n}(f, x)\right| \leqslant a_{\lambda, n}
$$

where $a_{\lambda, n}$ depends on $\lambda$ and $n$ only. Suppose that for $r=1,2, \ldots, p, \lambda_{r}$ is a number such that (8) holds everywhere in $E_{p}$. Then throughout $E_{p}$ we have

$$
\left|f\left(x_{1}, \ldots, x_{p}\right)-P_{n_{1}}, \ldots, n_{p}\left(f, x_{1}, \ldots, x_{p}\right)\right| \leqslant \sum_{r=1}^{p} a_{\lambda_{r}, n_{r}} .
$$

For example, if for $n=1,2, \ldots, K_{n}(x, t)$ is as in example II of section 10, then throughout $E_{p}$ we have

$$
\left|f\left(x_{1}, \ldots, x_{p}\right)-P_{n_{1}}, \ldots, n_{p}\left(f, x_{1}, \ldots, x_{p}\right)\right| \leqslant c \sum_{r=1}^{p} \lambda_{r} / n_{r}
$$

$c$ being the absolute constant mentioned there.

B. Assume that for $n=1,2, \ldots, \alpha_{n}$ and $\beta_{n}$ are numbers such that if $f$ is a real function, continuous and of period $2 \pi$ in $(-\infty, \infty)$, with modulus of continuity $\omega(\delta)(0 \leqslant \delta<\infty)$, then

$$
\max _{-\infty<x<\infty}\left|f(x)-P_{n}(f, x)\right| \leqslant \alpha_{n} \omega\left(\beta_{n}\right) .
$$

For every $\delta \geqslant 0$ and for $r=1,2, \ldots, p$ let $\omega_{r}(\delta)$ be given by (5) where now the $x_{j}, u$ and $v$ vary in $(-\infty, \infty)$, subject to $0 \leqslant v-u \leqslant \delta$. Then (with the notation (10)), (6) holds throughout $E_{p}$. For example, if for $n=1,2, \ldots, K_{n}(x, t)$ is as in example III of section 10, then throughout $E_{p}$ we have

$$
\left|f\left(x_{1}, \ldots, x_{p}\right)-P_{n_{1}}, \ldots, n_{p}\left(f, x_{1}, \ldots, x_{p}\right)\right| \leqslant 3 \sum_{r=1}^{p} \omega_{r}\left(n_{r}^{-1 / 2}\right) .
$$

\section{References}

[1] S. N. Bernstein, Démonstration du théorème de Weierstrass, fondeé sur le calcul des probabilités, Commun. Soc. Math. Kharkow (2), 13, 1-2 (1912-13).

[2] L. Fejér, Untersuchungen über Fouriersche Reihen, Math. Ann. 58, 51-69 (1904).

[3] L. Fejér, Über Interpolation, Göttinger Nachrichten, pp. 66-91 (1916).

[4] D. Jackson, Über die Genauigkeit der Annäherung stetiger Funktionen durch ganze rationale Funktionen gegebenen Grades und trigonometrische Summen gegebener Ordnung. Dissertation, Göttingen (1911).

[5] D. Jackson, On approximation by trigonometric sums and polynomials, Trans. Amer. Math. Soc. 13, 491-515 (1912).

[6] D. Jackson, The theory of approximation, New York (1930).

[7] G. G. Lorentz, Bernstein Polynomials, Toronto (1953).

[8] I. P. Natanson, Some estimates connected with the singular integral of de la Vallée-Poussin (Russian), Doklady Akad. Nauk SSSR 45, 290-293 (1944).

[9] I. P. Natanson, Constructive function theory, Volume I, (English translation) New York (1964).

[10] T. Popoviciu, Sur l'approximation des fonctions convexes d'ordre supérieur, Mathematica (Cluj) 10, 49-54 (1935).

[11] O. Shisha and B. Mond, The rapidity of convergence of the Hermite-Fejér approximation to functions of one or several variables, Proc. Amer. Math. Soc. 16, 1269-1276 (1965).

[12] Ch. J. de la Vallée-Poussin, Sur l'approximation des fonctions d'une variable réelle et de leurs dérivées par les polynômes et des suites limitées de Fourier, Bull. de l'Acad. Royale de Belgique, 193-254 (1908).

(Paper 70B3-182) 